\title{
Children and Television: Vicarious Socialisation Experiences
}

\author{
Anthony Potts ${ }^{\mathrm{a}}$, Nina Maadad ${ }^{\mathrm{b}}$, Marizon $\mathrm{Yu}^{\mathrm{c}}$ \\ ${ }^{a}$ University of Adelaide, Australia, Anthony.Potts@adelaide.edu.au, ORCID:0000-0002-2421-6581 \\ ${ }^{b}$ University of Adelaide, Australia, Nina.Maadad@adelaide.edu.au, ORCID: 0000-0002-4903-8400 \\ ${ }^{c}$ University of Adelaide, Australia, marizonyu@gmail.com,ORCID: 0000-0002-5171-2716
}

\begin{abstract}
This article contributes to the understanding of socialisation of children of Filipino immigrants in South Australia by examining their experiences and engagement with media, particularly television. Thirty children, aged 8-12 years, who participated in the study were mainly accessed through social networks. Children's names, which reflect Anglicised or Spanish influence to Filipinos, were changed to maintain ethical considerations. A qualitative methodological framework grounded the children's perspectives in symbolic interactionism. The study particularly focused on symbolic interaction concepts of the self (selves) and influence of others, forming perspectives, roles, attitudes of others and coping, as well as how socialisation experiences of children facilitated children's perspectives on media. These concepts are significant in understanding how children made sense of television content. This discussion on children's media socialisation is organised into two sections according to children's engagement with television and parental control of television watching. The children in this article have been exposed to both television content in the Philippines and Australia. Whilst the article focuses on a small cohort of primary school children, the theory and methodology could be applied to children of other cultures and as such may generate comparative results.
\end{abstract}

Keywords: media socialisation, primary school children, symbolic interaction, children of migrants, Australia

\section{Introduction: Symbolic interaction and this study on children and media}

In this article, the child is acknowledged as the subject of his or her own world and takes on perspectives through media socialisation. A child's world is increasingly structured around media technology, particularly electronic media such as television and the Internet. In the context of this article, experience with media refers to a process of learning that involved both the content and the use of the following media platforms - television, the Internet and gaming technology. Through the interaction with these media technologies, learning of children is not merely a passive response but an active engagement.

This article explored the perspectives of children from migrant Filipino backgrounds in South Australia on what they learnt (and were not allowed to learn) from television and how television viewing developed perspectives on their experiences. This article is part of a larger study on children of Filipino immigrants to Australia, which examined these children's perspectives on experiences - following migration - in four contexts: home, school, peers and the media (Potts, Maadad \& Yu, 2017; Yu, 2014). Thirty primary school children, 14 males and16 females, aged 8-12 years, were accessed through social networks and interviewed. Ethical standards and protocols were followed and applied. A qualitative research method informed by symbolic interactionism framed the analysis of children's media socialisation experiences through television viewing. The qualitative methodology involving the collection of information through in-depth interviews is consistent with the use of a symbolic interactionist framework in what Blumer (1969) suggested as direct examination of human group life and human conduct.

Fig. 1 represents the qualitative methodology used in the study and symbolic interactionism through its attendant concepts and practical parameters. Children's perspectives on television viewing were organised into codes as outlined 
in the figure. These themes were categorised into concepts informed by the symbolic interactionist theory. The process was iterative, from codes to categories to concepts. This qualitative analysis process allowed for theorisation of children's perspectives on media, particularly television viewing.

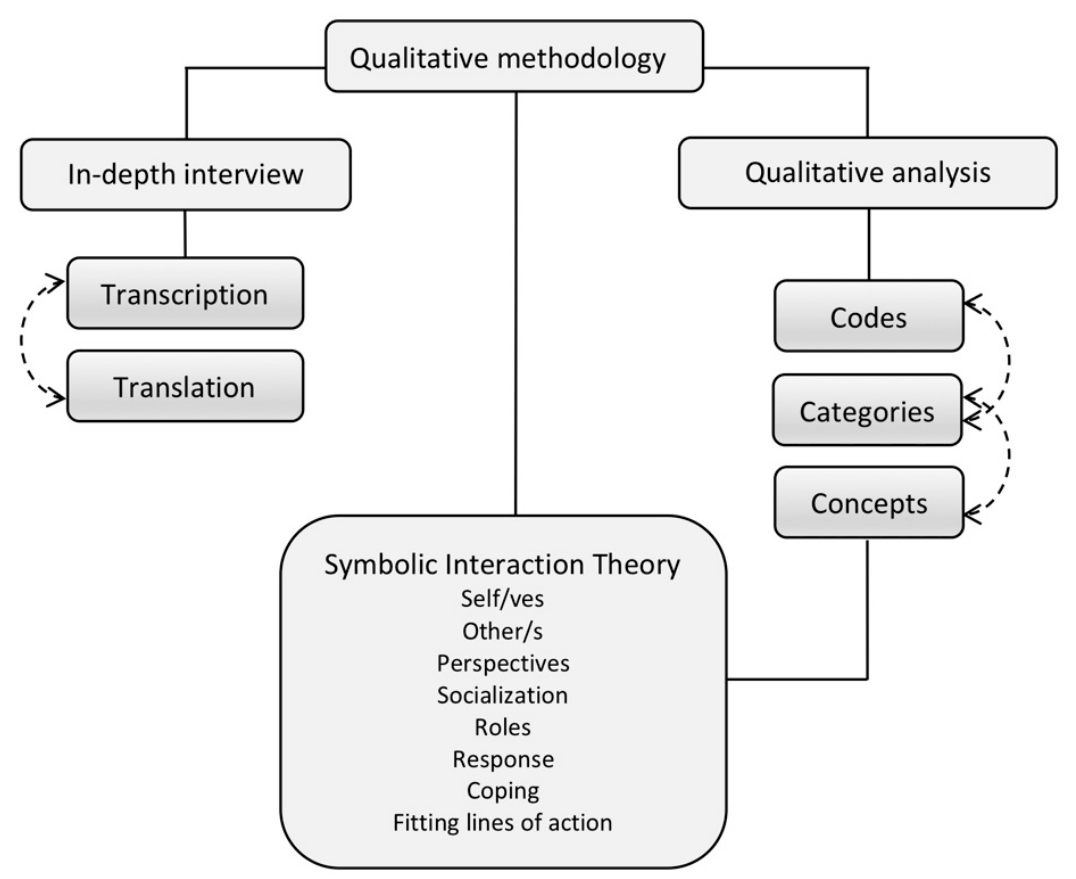

Fig. 1. Qualitative methodology and Symbolic Interactionism

Symbolic interactionist theory examines how individuals form concepts of selves and identities them through social interaction (Serpe \& Stryker, 2011; Mead, 1934), how individuals learn about and internalise culture through socialisation (Bush \& Peterson, 2013; Van de Walle, 2011; Berger \& Luckmann, 1966; Mead 1934) and how individuals develop adaptive skills and coping strategies through socialisation (Woods, 2012; Erickson, 2004; Potts, 1997; Pollard, 1982). The symbolic interactionist framework sees perspectives as 'frameworks through which people make sense of the world' (Woods, 1983, p. 7). In this article, concepts of selves, perspective-taking through taking the role of others, coping and anticipatory socialisation have been applied to what children learnt and how they developed perspectives to make sense of their world through watching television.

Many societies in the world today are characterised as increasingly structured around technology. Thompson (1995) described the culture of the advanced Western countries as 'highly mediatised'. Today's most advanced societies, even some urbanised areas of developing economies, are equipped with media technology that provide children with an array of entertainment and educational experiences. Cable television, computers, mobile phones, digital recorders or video cameras, gaming consoles, electronic gadgets for entertainment, information and communication, amongst other technological equipment, are instrumental in the advancement of the information age, and the rapid rise of what Castells (2000) described as the network society. The media that includes the Internet has become an integral part of the lives of this generation and thus provides considerable socialisation experiences for children. Children's media activities include television viewing, which has been identified as the most common activity of children, followed by computer use and gaming (AIFS, 2012; Rideout et al., 2010).

For Castells (2000), the network society suggests interconnectedness not only of technological systems but also of individuals, groups and society. Some of the key elements of networks that he identified are globalisation, power relationships and the role of media. These are seen as responsible for transforming and reshaping interactions and the structure of society. The media is influential in people's lives. However, media may not be a powerholder (Castells, 2010), in that it has the capacity to impose behaviour, but rather it is a space for the real powers behind it, and these are 'the networks of information exchange and symbol manipulation, which relate social actors, institutions, and cultural movements, through icons, spokespersons, and intellectual amplifiers' (Castells 2010, p. 379). 


\section{Media socialisation of children}

In a world characterised by digital information and communications technologies that pervade children's socialisation, it is important to understand the role of mass media and the new media/Internet in the socialisation of children. For Altheide (2003, p. 678), media contributes to the 'definition of situations and audience expectations and criteria for self-presentations'. Children see popular culture through media and often interact with and interpret media content by taking the perspective of media others, such as favourite television celebrities or books character. For Comstock (1978), media can be a source of vicarious socialisation that could challenge children's primary and secondary socialisation. Children are socialised into other people's lives and experiences, which they see in media (real or imaginary). These experiences may be similar or very different from their own. Even when the interaction is parasocial wherein children form one-sided relationships with media characters (Hoffner et al., 2008; Giles, 2003; Horton \& Wohl, 1956), children learn from the media (Barkhuus \& Brown, 2009; Kirkorian et al., 2008).

Play, for younger children, is often mediated through television shows such as Playschool, Sesame Street, Disney Channel, ABC Kids and Pokémon. Children's consumption of television, video games and the Internet has become so ubiquitous that it is now possible to use these technologies at the same time. For example, in households that are wired to the Internet, some individuals, including children, are now able to read about what they are currently watching on television just by searching the Internet using their tablets and smartphones. Even before watching a particular show on television, a parent can already research beforehand the classification of the show. For many parents coping with child rearing, children's network channels provide age-appropriate media content that allow parents to use the television as babysitter (Isaacs, 2011).

In Australia, most households reportedly own three or more television sets, three or more mobile phones, a gaming console, a DVD player and a computer, whilst 9 in 10 households have Internet connectivity (Australian Communications and Media Authority or ACMA, 2007). Children younger than 14 years spend at least 7 hours per week watching television and 11 hours a week on any screen content, including DVD, computer, gaming consoles and hand-held devices such as tablets, smartphones and iPads (ACMA, 2017).

Movie-going, film-viewing and watching TV programmes, such as ABC Kids, ABC Me, Cartoon Network and the like, have become regular activities for children. Movies and shows have also become significant topics of interest amongst children when they socialise in the playground. Many of these media activities have been acknowledged by parents and authorities as beneficial to develop children's social interaction and cultural literacy (ACMA, 2007; 2017). In a study conducted by the Australian Communications and Media Authority (2017), almost all parents recognised the educational benefits of the Internet for their children but expressed concerns about video gaming and other related electronic activities. Parents revealed that their children's engagement with media is not especially difficult to manage in the home, especially in terms of setting rules on television watching and use of computers and other gadgets, parents still encounter challenges when it comes to keeping up with the latest technological advances, particularly the Internet (ACMA, 2007). It is not surprising that some parents fall behind their children, when it comes to engagement with new media.

Some parents expressed concerns about children's exposure to violence in the media (ACMA, 2017, 2011, 2007). Although claims were made that children's aggressive behaviour was related to violence observed on television, recent research found that this relationship was ambiguous (Isaacs, 2011; Mitrofan et al., 2009; Browne \& HamiltonGiachritsis, 2008). Nevertheless, it cannot be discounted that media socialisation of children can have serious implications on their sense of selves.

The same concern may be said about advertisements that accompany children's shows and programmes. Some parents expressed concerns about the excessive advertising and the influence of advertisements on children (ACMA, 2017, 2011, 2007). As early as at the age of 5, most children are already able to distinguish television advertisements from programmes (Louis et al. 2013). However, around the age of 8, many children already demonstrate understanding of the persuasive intent of advertisements (Louis, et al., 2013). Whilst research on the specific effects of advertising on children have yielded mixed results, parents are warned to monitor their children's television viewing and educate themselves and their children to reduce the potential negative effects of advertising (Louis et al., 2013).

Whilst increased use of media by children contributes to their peer culture (Handel, et al., 2007; Lloyd, 2002), antisocial elements such as child predation, inappropriate content broadcast and cyber bullying also take place on the Internet and often victimises children. Parents, teachers, school administrators, the government and members of the media are called on to create and effectively implement a media policy for children (Burton, 2013; ACMA, 2010, 2008). 
In the Philippines, a study conducted by Turner International Asia Pacific for Cartoon Network - titled, The New Generations 2012 - described the media usage of Filipino children (Olchondra, 2012). A thousand children aged 7-14 years were surveyed about their media and Internet consumption. These children were randomly selected from the three major metropolitan areas of the Philippines - Metro Manila (80\%), Metro Cebu (10\%) and Metro Davao (10\%). Filipino children in the survey represented low-income to high-income socio-economic groups. The research group conducted face-to-face, in-home interviews and found that $65 \%$ of the respondents owned a mobile phone, $82 \%$ had Internet access in their homes and went online every week, $58 \%$ played online games and $52 \%$ logged in to social networking sites such as Facebook. The study concluded that many Filipino children had taken control of their digital lives through their engagement with media technology. Furthermore, the study revealed that children influenced the purchasing patterns of their parents and guardians when it came to technology-related products.

Seven of 10 Filipino children watch television programmes for an average of 4-5 h each day (Osorio, 2014). NerissaSto Tomas, a psychologist and parental coach, commented in an interview to a Filipino newspaper that 'television has become like a babysitter in many Filipino households, especially for children whose parents work outside the home' (Valisno, 2012, para. 4).

Media as a source of information may actually help children to find topics that are limited by their interaction with other socialisation agents (Kirkorian et al., 2008; Louie, 2003). Examples are children watching an educational programme or a show on the latest dance craze or when children need information about homework in school and their parents are unavailable or too busy to help.

With Internet, children are more exposed to media content alongside television compared with children generations ago. Media content is loaded with stereotypes, anti-social and unrealistic behaviours that contribute to negative socialisation. At the same time, it can be also laden with constructive content and values that enhance positive socialisation of children (Dubow et al., 2007). Children's engagement with media provides learning opportunities and socialisation experiences, including virtual and vicarious experiences, which allow them to view and think about their own socialisation experiences in the home, in the school, with peers and in other socialisation contexts.

\section{Perspectives on media socialisation: children's TV viewing experiences}

Children's experiences with media included interaction with television, computer activities and video gaming. Table 1 shows the variety of media technology used by participants. Availability of and access to media technology suggested a relationship between media and socialisation of children.

Table 1. Ownership of media-related technology.

\begin{tabular}{lc}
\hline Media devices/attributes & Total $(f)$ \\
\hline Television (with DVD players) $^{*}$ & 24 \\
Radio* $^{*}$ & 24 \\
Internet connection* $^{*} 24$ \\
The Filipino Channel (TFC on cable network)* & 16 \\
Family computer, laptop (shared)* & 24 \\
Owned a personal computer & 4 \\
Owned a Facebook account & 17 \\
Used parents' Facebook account & 5 \\
No Facebook account; not interested & 8 \\
Gaming consoles (Xbox, Wii, PlayStation, PSP, DS) & 16 \\
Other media devices owned or shared with siblings (iPad, iPod, mobile, & 7 \\
Tablet) & \\
\hline *Sibling participants who shared TFC subscription, gaming console units and other devices were counted as 1 \\
of 24 (families). \\
**The rest were counted as individuals ( $\mathrm{n}=30$ ).
\end{tabular}

Media-related items owned by children or their families included television sets with DVD players, radios, cable and Internet, computers, mobile devices (including phones, tablets or iPads) and gaming consoles. Media technology available to children fostered a Westernised identity as characterised in the network society. Media-related technologies 
provided opportunities for media experiences and related socialisation activities, in which children developed perspectives on language, consumerism, career preferences and relationships with family, peers and virtual others.

\subsection{Perspectives on television viewing}

The most common media activity of children was television viewing. Television activities involved watching news, films, music videos and other programmes through standard network channels and cable networks. All children and their families owned at least one television set and DVD player. The television provided children and their families with both entertainment and information.

\subsubsection{Learning about the Philippines through Filipino programmes}

Media socialisation experiences of children were informed by prior engagement with the media in the Philippines. The media companies in the Philippines were largely owned by private corporations. Most media content was highly westernised. Many households in the Philippines had access to networks through cable satellite. Children's families subscribed to cable television in the Philippines. Shows from the HBO Channel, Cartoon Network, Disney Channel and Nickelodeon were familiar to children. Children had developed Americanised identities in terms of television viewing. In Australia, television viewing was a regular activity for the children in this study/article. Television viewing allowed family members to spend time together and to keep abreast of contemporary developments in the Philippines. Television viewing formed part of children's cultural repertoires from which they learnt about Filipino celebrities, the environment and the Filipino language.

As shown in Table 1, most children had cable television and were subscribers to The Filipino Channel or TFC (ABSCBN Global, 2007) that televised Filipino movies and television shows $24 \mathrm{~h}$ a day, 7 days a week. Children without TFC in their homes still accessed Filipino movies from DVDs, from the Internet or by visiting Filipino friends who had TFC. Accessibility to TFC was an important indicator of children's connection with the Philippines.

Some children revealed that TFC was on from morning till night time in their house. For Jenny, who also echoed other participants' views, 'I like watching TFC. It's a channel for Filipino people only. It has news, shows, sports show. The shows are like movies'.

Children who had TFC in their homes named famous television personalities from the Philippines and controversies surrounding them. They learnt Filipino humour from comedians such as those in noontime variety shows. They learnt about Filipino melodrama and narratives that featured fantasy and neorealism. Some Filipino celebrities also endorsed fashion brands and products. Children received these advertising messages from television and its celebrities. Tina enjoyed watching through TFC, a noon-time show aired in the Philippines, 'Showtime... because the presenters are funny and they always make jokes'.

Children learnt Filipino contemporary culture through media celebrities. Children's interaction with these celebrities was one sided (para-social) and socialisation was vicarious. However, these media personalities served as a reference group for children in organising their selves and their links with the Philippines. Children became aware of the issues affecting Filipinos through the news, such as poverty. Some themes in soap operas that portray lives of Filipinos also depict both poor and rich. These provided references for children to evaluate their own lives in Australia.

Children who watched Filipino news learnt about the country's natural environment and that the country was devastated by typhoons and floods. Given the frequency of natural disasters, children felt safe in Australia as stated by a participant named Grace, 'There's lots of floods [in the Philippines], we watched this in TFC'.

Children who watched TFC, Filipino news and DVDs were socialised to the Filipino/Tagalog language. A number of children understood Filipino movies even when they could not fluently speak Tagalog. Children were able to give a summary of the movie they watched, as exemplified by Mardi:

Wako Wako [television show] There was a fountain and if you want to make a wish, you have to bring something that is really important to you and you have to make a wish and drop the important thing down the fountain and there's someone living down that fountain that makes your wish to come true.

Children's understanding of the Tagalog language was maintained through TFC. With TFC in the homes of twothirds of children and through Filipino programmes, they had an awareness of lifestyle in the Philippines including the illusory world of show business, the physical and social environment and the Tagalog language. Some programmes that children watched on TFC had generic plots that presented close analogies to real life in the Philippines. Children learnt about real-life situations from television. Other shows that children watched were fictional. Children learnt about the 


\section{Children and television: Vicarious socialization experiences \\ Potts, Maadad, Yu}

world of make-believe that enhanced their imagination. Children were both entertained and informed by TFC regarding the Philippines. Children appropriated their core Filipino selves through language in Filipino programmes on television. The media content and its accompanying celebrities in the Philippines provided children with reference groups for their present lives in Australia.

\subsubsection{Learning from English-language television programmes}

Television and films exposed children to languages other than their mother tongue. As reported in the previous section, children learnt Tagalog language by watching television programmes on TFC and they learnt to speak English by watching English-language programmes. Children learnt to pronounce words with an Australian accent. A few children, who watched a lot of Anime (Japanese cartoon fiction), learnt Japanese phrases and words featured in these English-dubbed or English-subtitled shows.

When I came here, all I knew was 'How are you?' and just simple words. But by watching TV, I learnt English in Australia. Yeah, I did. I came here in Australia when I was six years old. I watched really kiddie shows Hi-5, Disney and a lot of Hannah Montana. (Ellen)

For children, watching English-language shows helped them learn more English. They learnt words, expressions and pronunciations that helped them communicate more fluently in English. From watching television programmes, children were able to see themselves from the viewpoint of generalised others who spoke English.

Children were entertained by English-language programmes, for example, shows on ABC3 such as Stoked and Big Babies. Together with their parents and siblings, children enjoyed shows such as Modern Family and Master Chef. They watched Hollywood movies on DVD and Japanese Anime such as Naruto, Pokémon and Bakugan. Children watched American, Australian and Filipino television programmes and movies. Preference for such shows indicated that they were attuned to both their Westernised and Asian selves.

Television and movie preferences were fostered by parents and significant others, but most children developed their own.

Watching TV, Modern Family...My mum and dad like watching it. (James)

Angelina Ballerina... my brother doesn't like watching it but I watch it, even though and he still watches it, and then it's his turn and he [watches]Elijah and Julius, it's action... solving mystery crimes. (Nina)

Children knew what entertained their parents and siblings. This did not necessarily translate into actually liking the others' tastes in television programmes. Children accommodated the tastes of their significant others when it came to television programmes. Through watching television with their families, children developed negotiation skills as they adjusted their preferences to the choices of others. This is what Mead (1934), Blumer (1969) and Prus (2010) called fitting one's lines of action as coping strategy in social situations.

\subsubsection{Learning consumerism through television}

Children viewed television as a commodity in their daily lives. Most of the television programmes they watched were laden with advertisements. These advertisements featured merchandise such as toys and food. Troy was alerted to his favourite toy via television. This toy had an anime storyline and was in a television series.

Bakugan toys ... It is like a ball, and there is a game... I saw it on TV, internet, and at school. We play it with cards, we roll the Bakugan and it will stand. (Troy)

Children were socialised to be consumers of products advertised on television. These ranged from toys, clothes, accessories, gadgets, games and other products. Children's consuming selves were formed through a complex interplay of taking the perspective of others. Family members socialised children into a shopping culture. Children also assumed the perspectives of peers with whom they played games and the products that came with these games. In addition, they also took the perspectives of virtual others in advertisements. Through television, the children learnt to borrow ideas, styles and strategies from the promoters of products (Hage \& Powers 1992; Mead 1934). A consumerist self was formed and fostered via television viewing. 


\section{Children and television: Vicarious socialization experiences Potts, Maadad, Yu}

Educational programmes such as Hi-5, Disney and Playschool promoted their merchandise to children. Children who watched these not only learnt to speak English from them and consume their merchandise but they also listened to the music that accompanied these programmes. They formed preferences for certain music and entertainers through television.

Now, my favourite singer is Bruno Mars. It used to be Guy Sebastian. I like Bruno Mars better, and he's like my type and I like the kind of songs he makes like Runaway Baby, the Lazy Song. (Ben)

Children developed peer culture through shared tastes for music and its artists. Some appropriated their identities to certain artists. Children developed para-social relations with media personalities who could be referred to as virtual others. Children knew the celebrities but the interaction was one sided. Nevertheless, celebrities were seen as reference groups for children's peer culture.

\subsubsection{Learning history and general information}

Documentaries and movies provided historical information. Some children watched ABC3 and its depiction of historical events in Horrible Histories. One child illustrated how he/she learnt about aspects of Australian life in the movie, Australia.

Sometimes my father would play the DVD. You know the movie Australia? When my father played the movie Australia, we all watched it and saw the life in Australia and how it came to be multicultural. (Amiel)

Despite the mythologised nature of the film (Luhrmann 2008), key historical periods, such as World War II, were represented and these gave glimpses of Australian life at critical times. Historical events portrayed on television served to arouse children's interest in history. Children saw how generalised others lived and from this made sense of how they were linked to society (Mead 1934).

\subsubsection{Learning about careers through television}

Television socialised children to certain future roles and occupations as illustrated by participants who saw future career prospects suggested on television.

What do you want to become in the future? (Researcher)

To be famous on TV like a singer or dancer (Jenny)

Army, because of the guns, I saw them on the television. (Amy)

To be a singer and to meet celebrities (Chloe)

Children's future aspirations in life were influenced by television. Children saw television celebrities as role models for future careers. Some wanted to be famous like the celebrities on My Kitchen Rules.

I like cooking and watching My Kitchen Rules, Junior Master Chef, Master Chef, and lots of ABC 3. I wanna go to the University and practice culinary arts. I want to be Manu Feildel's and Peter Evans' apprentice chef. I want to own a restaurant. I want to become famous. (Sally)

Children's ability to imagine future situations were informed and influenced by television. Media portrayed glamorous people with their social values, behaviours and attitudes. Many television shows represented roles that participants found attractive. Children responded to these influences by developing preferences for some careers over others. These had socialising influences on future career aspirations. Through role-taking, they assumed the perspectives and roles of celebrities. Even if the identification with media celebrities was wishful (Hoffner et al., 2008), through anticipatory socialisation by the media, children were provided with options for future careers. 


\subsection{Parental regulation of television}

Parents monitored what children watched. Most children watched ABC Me and children's cartoon shows on other networks, usually unsupervised. However, with television shows and movies that needed parental guidance, children watched with their parents. Movies with fighting scenes were allowed only when their parents were present. Some mature content was not permitted.

We usually watch movies here in the lounge room; like we got a TV so we watch movies here like action, sometimes comedy and all that. On Mclassified movies, it depends if it has stuff I can't see. But fighting is ok. But if it's a lot, I won't watch it. (Sally)

While parents allowed shows and movies with mild degrees of violence and mild adult and supernatural content, children accepted parental regulation of television and movie viewing. They adjusted their responses regarding restricted media content. They watched shows from children's channels and cartoons on other networks. They watched movies under parental guidance. Children refrained from watching adult material on television. They were also aware of the make-believe nature of many shows and films they watched.

Children were told by parents to complete homework before television. This was an enforced rule. Children complied with this as illustrated by the following responses. They did not have any choice, and they were aware of the consequences of defiance. For Ben, 'After writing my homework, I would slouch on the lounge and watch TV, until Mum says, "Go to sleep.",

Parents controlled television viewing to socialise children to the value of school work before leisure. Children indicated the dangers of being distracted by television viewing while doing school work, as explained by Carlo, 'Yes, I have to study here in the lounge. The TV must be turned off, I need to concentrate, and there should be no distraction.' The older children in the study did not have to be told by parents to do their homework before watching television.

Children developed the habit of doing their homework before watching television. They were aware of the repercussions of watching television while doing their homework. Children learnt to adjust their television-viewing behaviours to accomplish school-related work.

Children's television viewing on school days was regulated to foster proper functioning at school. This formed children's repertoire of routines. A few participants watched television before going to school. Children were socialised to school morning rituals that parents enforced to structure their school day. Children strategically complied with these routines. By doing so, they coped with the daily demands of schooling.

After waking up I still feel tired, I go straight to the lounge, watch TV, then I wake up, Mum prepares my breakfast, then I get ready to walk to school. (Carlo)

We don't really have time to watch TV unlike other kids in school, and then we get our bags ready, and we make sure everything's in place and then we go to school. (Liz)

Television and movie viewing for children was a source of entertainment and information. Through television, socialisation to appropriate media content structured children's viewing habits. Some media content provided anticipatory socialisation for future careers. Children learnt about the Philippines, Australia and the rest of the world through television. Some improved their language speaking skills or learnt to speak other languages, particularly in the English language, through television. Children formed preferences for products that were featured on television. In terms of viewing habits, children learnt to adjust their behaviour by complying with parental regulation and control, which organised their school-day routines.

\section{Conclusion}

The children exercised control of their networked lives despite the temptations of a media-rich world. With digital media technology, children entertained themselves and accessed information even from television viewing. Children developed perspectives on their Filipino selves through watching Filipino programmes and news. Children learnt to maintain aspects of their Filipino selves through language and familial values as they strengthened their ties with the Philippines and its culture. Children nurtured their Westernised selves as they engaged with English-language media content. Children developed selves whose preferences were not limited to only one culture.

By taking the role of some media personalities, children developed perspectives on careers. Anticipatory socialisation to future careers was carried out by the media through the portrayals of roles, both real and illusory. 
Aware of parental control and school regulation of media content and activities, children fitted their responses to regulation by being compliant lest their media devices were withheld due to misbehaviour, disobedience or failure to accomplish tasks. Even when regulations structured children's repertoire of practices, children exercised self-regulation by taking the perspectives and attitudes of parents and teachers.

Children watched television shows with siblings and parents. Children learnt to use media content and technologies at home. They developed perspectives on relationships with others, language, consumerism, the environment, career preferences and regulation of media use. Regardless of the home-regulated children's use of television and even media devices, their engagement with media through television and their responses to the challenges associated with digital technology not only provided opportunities for learning and interaction but also equipped them for future roles in the network society, vicariously and otherwise.

\section{References}

ABS-CBN Global. (2007). ABS-CBN Global: in the service of the Filipino worldwide. Retrieved from http://www.abscbnglobal.com/Regions/Australia/tabid/149/Default.aspx

ACMA (2007). Media and communications in Australian homes. Retrieved from http://www.acma.gov.au/WEB/STANDARD/pc= PC_310262

Australian Bureau of Statistics (2012). Reflecting a nation: stories from the 2011 Census, 2012-2013. Retrieved from http://www.abs.gov.au/ausstats/abs@.nsf/mf/2071.0

Australian Institute of Family Studies.(2012). Growing up in Australia: the longitudinal study of Australian children, Retrieved from http://www.growingupinaustralia.gov.au/

Altheide, D.L. (2003). The mass media. In L.T. Reynolds \& N.J. Herman-Kinney (Eds), Handbook of symbolic interactionism (pp. 657-683). Walnut Creek, CA: AltaMira Press.

Australian Communications and Media Authority, ACMA (2017). Children's television viewing and multi-screen behaviour Analysis of 2005-16 OzTAM audience data and 2017 survey of parents, carers and guardians. Melbourne: ACMA.

Australian Communications and Media Authority, ACMA (2011). Digital Australians- expectations about media content in a converging media environment. Melbourne: ACMA.

Australian Communications and Media Authority, ACMA (2010). Trends in media use by children. Melbourne: ACMA.

Australian Communications and Media Authority, ACMA (2008). Media use by girls and boys. Canberra: Commonwealth of Australia.

Barkhuus, L.\& Brown, B. (2009). Unpacking the television: user practices around a changing technology, $A C M$ Transactions on Computer-Human Interaction, 16(3), 1-22.

Berger, P.L.\& Luckmann, T. (1966). The social construction of reality: a treatise in the sociology of knowledge. NY: Penguin Books.

Blumer, H. (1969). Symbolic interactionism: perspective and method. NJ: Prentice-Hall, Inc.

Browne, K.D.\& Hamilton-Giachritsis, C. (2008). The influence of violent media on children and adolescents: a publichealth approach. The Lancet, 365 (9460), 702-710.

Burbary, K. (2011). Facebook demographics revisited - 2011 statistics. Retrieved from http://www.kenburbary.com/

Burke, P.J. (2006). Contemporary social psychological theories. CA: Stanford Social Sciences.

Burton, L. (2013). Raising children network: the Australian parenting website. Retrieved from http://raisingchildren.net.au/articles/media_benefits.html

Bush, K.R.\& Peterson, G.W. (2013). Parent-child relationships in diverse contexts. In G.W. Peterson \& K.R. Bush (Eds), Handbook of marriage and the family (pp. 275-302). NY: Springer.

Cahill, D., Birchall, G., Fry, I., Vine, E., Black-Gutman, D.\& McLaughlin, D. (1996).Immigration and schooling in the 1990s. Canberra: Department of Multicultural Affairs.

Cartoon Network \& Turner International. (2012). The new generations 2012 survey, Manila, Philippines. Retrieved from http://www.serdef.org/archives/847

Castells, M. (2010). End of millennium: the information age: economy, society, and culture. MA: Wiley-Blackwell.

Castells, M. (2000). The rise of the network society.MA: Wiley-Blackwell.

Cohen, L., Manion, L.\& Morrison, K. (2011). Research methods in education. London; NY: Routledge.

Comstock, G. (1978). The impact of television on American institutions. Journal of Communication, 28(2), 12-28.

Cruz, I. (2010). Pros \& cons in the $\mathrm{K}+12$ basic education debate, Multilingual Philippines: do not leave your language alone. Retrieved from http://mlephil.wordpress.com/2010/10/14/pros-cons-of-the-k12-debate/

Erickson, K. (2004). To invest or detach? Coping strategies and workplace culture in service work. Symbolic Interaction, 27(4), 549-572.

Giles, D. (2003). Media psychology. NJ: Lawrence Erlbaum Associates. 
Hage, J.\& Powers, C.H. (1992). Post-industrial lives: roles and relationships in the 21st century. CA: Sage Publications.

Handel, G., Cahill, S.E.\& Elkin, F. (2007). Children and society: The sociology of children and childhood socialization. NY: Oxford University Press.

Hoffner, C.A., Levine, K.J. \& Toohey, R.A. (2008). Socialization to work in late adolescence: the role of television and family. Journal of Broadcasting \& Electronic Media, 52(2), 282-302.

Horton, D. \& Wohl, R.R. (1956). Mass communication and para-social interaction: observations on intimacy at a distance. Psychiatry, 19(3), 215-229.

Isaacs, D. (2011). Television and children. Journal of Paediatrics and Child Health, 47(3), 71-72.

Kirkorian, H.L., Wartella, E.A.\& Anderson, D.R. (2008).Media and young children's learning. Future of Children, $18(1), 39-61$.

Levine, K.J. \& Hoffner, C.A. (2006). Adolescents' conceptions of work: what is learned from different sources during anticipatory socialization? Journal of Adolescent Research, 21(6), 647-669.

Lloyd, B.T.N. (2002). A conceptual framework for examining adolescent identity, media influence, and social development. Review of General Psychology, 6(1), 73-91.

Louie, J. (2003). Media in the lives of immigrant youth. New Directions for Youth Development, 2003(100), 111-130.

Louis, W., Burke, S., Pham, H.\& Gridley, H.(2013).Media representations and responsibilities: psychological perspectives. Melbourne: Australian Psychological Society.

Luhrmann, B.(2008). How we made the epic of Oz', Interview by Killian Fox. Retrieved fromhttp://www.theguardian.com/film/2008/nov/02/baz-luhrmann-nicole-kidman-australia

Mead, G.H. (1934). Mind, self, and society: from the standpoint of a social behaviorist. IL: The University of Chicago Press.

Mitrofan, O., Paul, M. \& Spencer, N. (2009). Is aggression in children with behavioural and emotional difficulties associated with television viewing and video game playing? a systematic review. Child: Care, Health \& Development, 35(1), 5-15.

Morrison, M. (2012).Understanding methodology. In A.R. Briggs, M. Coleman \& M. Morrison (Eds), Research Methods in Educational Leadership and Management. CA: Sage Publications.

Olchondra, R.T. (2012). Children influence buying patterns, poll says. Retrieved from http://business.inquirer.net/61337/children-influence-buying-patterns-poll-says

Osorio, B.(2014). Filipino consumers in high definition. Retrieved from http://www.philstar.com/business-life/2012-0924/852140/filipino-consumers-high-definition

Potts, A.(1997). College academics. Charlestown, NSW: William Michael Press.

Potts, A., Maadad, N. \& Yu, M. (2017). "My friends are there": Constructions of schooling of children of Filipino immigrants in South Australia. Cogent Education, 4(1), 1-17.

Prus, R.C. (2010). Ethnographic comparisons, complexities and conceptualities: generic social processes and the pragmatic accomplishment of group life. Comparative Sociology, 9(4), 496-527.

Rideout, V.J., Foehr, U.G.\& Roberts, D.F.(2010). Generation M2: media in the lives of 8- to18-year-olds. Retrieved from http://www.kff.org/entmedia/upload/8010.pdf

Roberts, M.(2013). TV time 'does not breed badly behaved children'. Retrieved from http://www.bbc.co.uk/news/health-21923930.

Serpe, R.T. \& Stryker, S.(2011). The symbolic interactionist perspective and identity theory. In S.J. Schwartz, K. Luyckx \& V.L. Vignoles (Eds), Handbook of identity theory and research (pp. 225-248). NY: Springer.

Staff writer. (2012). Kids drive local mobile boom. Retrieved from http://www.marketing-interactive.com/news/32754

Thompson, J.B. (1995). The media and modernity: a social theory of the media. CA: Stanford University Press.

Valisno, J.O.(2012). For the sake of the children. Retrieved from http://www.bworldonline.com/weekender/content.php?id=52681

Van de Walle, G. (2011). 'Becoming familiar with a world': a relational view of socialization. International Review of Sociology, 21(2), 315-333.

Woods, P. (1983). Sociology and the school: an interactionist viewpoint. London: Routledge.

Woods, P. (2012). The development of pupil strategies. In P. Woods (Ed.), Pupil strategies: explorations in the sociology of the school, Oxford; NY: Routledge.

Yu, M. G. (2014). Perspectives of primary school children of Filipino immigrants on their home and school experiences in South Australia. (Thesis). University of Adelaide. Retrieved from http://hdl.handle.net/2440/82557 